\title{
¿On the Sensitivity of Convectively Coupled Equatorial Waves to the Quasi-Biennial Oscillation ${ }^{\mathscr{Q}}$
}

\author{
S. AbHik, Harry H. Hendon, AND MATthew C. WheEler \\ Bureau of Meteorology, Melbourne, Australia
}

(Manuscript received 9 January 2019, in final form 5 June 2019)

\begin{abstract}
The seasonal-mean variance of the Madden-Julian oscillation (MJO) in austral summer has recently been shown to be significantly ( $p<5 \%$ ) enhanced during easterly phases of the quasi-biennial oscillation (QBO). The impact is large, with the mean $\mathrm{MJO}$ variance increasing by $\sim 50 \%$ compared to the QBO westerly phase. In contrast, we show using observed outgoing longwave radiation that seasonal variations for convectively coupled equatorial Kelvin, Rossby, and mixed Rossby-gravity waves are insensitive to the QBO. This insensitivity extends to all high-frequency (2-30-day period) and the non-MJO component of the intraseasonal (30-120-day period) convective variance. However, convectively coupled Kelvin wave variability shows a modest increase $(\sim 13 \%)$ that is marginally significant $(p=10 \%)$ during easterly phases of the QBO in austral autumn, when Kelvin wave activity is seasonally strongest along the equator. The mechanism of impact on the Kelvin wave appears to be similar to what has previously been argued for the MJO during austral summer. However, the more tilted and shallower vertical structure of the Kelvin waves suggests that they cannot tap into the extra destabilization at the tropopause provided by the easterly phase of the QBO as effectively as the MJO. Lack of impact on the convectively coupled Rossby and mixed Rossby-gravity waves is argued to stem from their horizontal structure that results in weaker divergent anomalies along the equator, where the QBO impact is greatest. Our results further emphasize that the MJO in austral summer is uniquely affected by the QBO.
\end{abstract}

\section{Introduction}

The quasi-biennial oscillation $(\mathrm{QBO})$ refers to the alternating westerly and easterly winds in the equatorial stratosphere that descend from the upper to lower stratosphere with period of $\sim 28$ months (e.g., Baldwin et al. 2001). The QBO is well understood to be driven by the momentum fluxes associated with upward-propagating waves that originate in the equatorial troposphere, primarily forced by tropical convection (Lindzen and Holton 1968). Although the QBO is a stratospheric phenomenon, its impact

¿ Denotes content that is immediately available upon publication as open access.

Supplemental information related to this paper is available at the Journals Online website: https://doi.org/10.1175/JCLI-D-190010.1.s1.

Corresponding author: Harry H. Hendon, harry.hendon@ bom.gov.au extends down to the tropopause where, for instance, temperatures are lower than normal when the QBO winds are easterly in the lower stratosphere. This downward extension to the tropopause and below raises the possibility that the QBO may also influence tropical convection. Previous studies (e.g., Collimore et al. 2003; Liess and Geller 2012) found that deep tropical convection is modestly enhanced over the Indo-Pacific warm pool when the QBO winds in the lower stratosphere are easterly. Thin cirrus at the tropopause is also observed to be increased during the easterly phase of the QBO when temperatures at the tropopause are decreased (Davis et al. 2013; Son et al. 2017). The promotion of deeper convection and more cirrus cloud in response to the destabilization of the tropopause during the easterly phase of the QBO has been reproduced in a cloud-resolving model (Nie and Sobel 2015).

A more substantial impact of the QBO on the variability of the Madden-Julian oscillation (MJO) has recently been uncovered (e.g., Yoo and Son 2016; Marshall et al. 2017; Nishimoto and Yoden 2017; Son et al. 2017). 
The seasonal-mean variance of the MJO during austral summer, as measured by MJO bandpass-filtered OLR variance or the variance of other common MJO indices, is observed to be $\sim 50 \%$ greater when the QBO is in its easterly phase in the lower stratosphere compared to the westerly phase of QBO. Equivalently, the QBO in the lower stratosphere accounts for up to $50 \%$ of the year-toyear variability of the seasonal-mean variance of the MJO during austral summer (Marshall et al. 2017).

The ramifications of this QBO-MJO relationship are great: it challenges the fundamental notion of what controls the activity of the MJO, suggesting that variations around the tropopause (e.g., Nishimoto and Yoden 2017; Son et al. 2017; Hendon and Abhik 2018) might be as important as lower-tropospheric variations in moisture that are fundamental to many theories of the MJO (e.g., Sobel and Maloney 2013; Wang and Chen 2017). Furthermore, individual MJO events are also found to be more predictable during the easterly phase of the QBO (e.g., Marshall et al. 2017), raising the possibility of more confident and potentially more useful multiweek climate predictions during the easterly phase of the QBO. Although an impact of the QBO on MJO has been demonstrated in a limited area model with imposed MJO boundary conditions (Martin et al. 2019), an impact of the QBO on the MJO has yet to be simulated using a long free run of a climate model with selfgenerated MJOs (e.g., Lee and Klingaman 2018). Furthermore, the seasonality of the association of the MJO with the QBO, whereby the association is confined to the austral summer season, is yet to be fully explained. It thus remains an important question as to whether and how the QBO may influence tropical convection at different time scales.

The present study investigates the impact of the QBO on the seasonal-mean amplitude of convectively coupled equatorial waves (CCEWs). CCEWs refer to tropical convection and associated circulation anomalies that have the structure and propagation characteristics of the linear equatorially trapped wave modes permitted by shallow water theory (Matsuno 1966) but defined using a smaller equivalent depth than is inferred from the dry dynamics (e.g., Wheeler and Kiladis 1999). The CCEWs include equatorial Kelvin, Rossby, mixed Rossby-gravity, and inertio-gravity wave modes. In addition to the MJOs, these CCEWs account for a substantial fraction of tropical convective variability (Wheeler and Kiladis 1999). They modulate tropical weather-climate variability and provide a source of tropical predictability (e.g., Wheeler and Weickmann 2001).

Diagnosing an impact of the QBO on the seasonalmean amplitude of CCEWs will test our understanding of how the QBO modulates tropical convection and especially the MJO. We will assess the hypothesis of Hendon and Abhik (2018) that the horizontal and vertical structure of the MJO, especially its deep vertical structure that extends to and above the tropopause (e.g., Kiladis et al. 2005), allows for it to be promoted by the destabilization about the tropopause during easterly phases of the QBO. The temperature and wind structure of CCEWs also extend through the depth of the troposphere up to the tropopause (e.g., Kiladis et al. 2009), so they too may feel an impact of the QBO at the tropopause. However, their vertical structures are typically more tilted in the upper troposphere (Wheeler et al. 2000) and so may not interact with the QBO in the same fashion as does the MJO. Moreover, the CCEWs, other than the Kelvin wave and some of the high-frequency inertio-gravity waves, do not have an equatorially centered convective anomaly, and so may not "feel" the QBO as does the MJO. Exploring impacts of the QBO on CCEW activity may also provide improved understanding of the large-scale controls on organized tropical convection and possibly underpin improved predictions of tropical weather and climate.

\section{Data and methods}

The phase of the QBO is monitored using the Freie Universitat Berlin (FUB) zonal wind index at $50 \mathrm{hPa}$ (Naujokat 1986). The FUB index is based on radiosonde observations from Singapore, but it well represents the zonal-mean zonal wind variation associated with the QBO. We define westerly and easterly phases of the QBO (hereafter QBOW and QBOE, respectively) when the 3-month running-mean anomaly exceeds +0.5 and -0.5 standard deviations, respectively. The list of QBOW and QBOE years during 1979-2015 is provided in Table 1. When the QBO zonal winds at $50 \mathrm{hPa}$ are westerly, temperatures are anomalously warm below this level down to the tropopause, and vice versa for the easterly phase, reflecting the fact that $\mathrm{QBO}$ variations of equatorial zonal wind and temperature are in thermal wind balance (e.g., Son et al. 2017).

We diagnose CCEWs using 37 years (1979-2015) of daily averaged NOAA polar-orbiting satellite estimates of outgoing longwave radiation (OLR), which have been interpolated in space and time to remove missing data (Liebmann and Smith 1996). The OLR data, which are available globally on a $2.5^{\circ}$ grid, are used as a proxy for deep convection.

The CCEWs are identified using space-time spectral analysis and filtering of OLR anomalies, following the approach in Wheeler and Kiladis (1999). 
TABLE 1. QBOE and QBOW years and corresponding values of the standardized FUB index. The excluded coinciding ENSO years are shown in italics with ONI values in parentheses.

\begin{tabular}{|c|c|c|c|c|}
\hline & DJF & MAM & JJA & SON \\
\hline QBOE years & $\begin{array}{l}\text { 1979/80: }-1.86 \\
\text { 1984/85: }-1.59(-1.0) \\
\text { 1989/90: }-1.63 \\
\text { 1996/97: }-1.52 \\
\text { 1998/99: }-1.73(-1.5) \\
\text { 2001/02: }-1.31 \\
\text { 2003/04: }-1.55 \\
\text { 2005/06: }-1.31(-0.8) \\
\text { 2007/08: }-1.55(-1.6) \\
\text { 2012/13: }-1.20 \\
\text { 2014/15: }-0.86\end{array}$ & $\begin{array}{l}\text { 1980: }-1.34 \\
\text { 1982: }-1.11 \\
\text { 1987: }-0.65(0.9) \\
\text { 1990: }-0.91 \\
\text { 1992: }-0.57(1.3) \\
\text { 1997: }-0.50 \\
\text { 2006: }-1.14 \\
\text { 2008: }-1.11(-0.9) \\
\text { 2010: }-1.07 \\
\text { 2013: }-1.35 \\
\text { 2015: }-1.45(0.8)\end{array}$ & $\begin{array}{l}\text { 1979: }-0.83 \\
\text { 1982: }-1.76(0.8) \\
\text { 1984: }-1.85 \\
\text { 1987: }-1.95(1.5) \\
\text { 1992: }-1.93 \\
\text { 1994: }-1.96 \\
\text { 1996: }-1.42 \\
\text { 1998: }-1.66(-0.8) \\
\text { 2001: }-1.13 \\
2005:-0.53 \\
\text { 2007: }-0.77 \\
\text { 2010: }-1.86(-1.0) \\
2015:-0.79(0.8)\end{array}$ & $\begin{array}{l}\text { 1979: }-1.61 \\
\text { 1984: }-2.04 \\
\text { 1989: }-1.17 \\
\text { 1992: }-1.56 \\
\text { 1994: }-2.16 \\
\text { 1996: }-1.70 \\
\text { 1998: }-1.90(-1.4) \\
\text { 2001: }-1.63 \\
\text { 2003: }-1.06 \\
\text { 2005: }-1.31 \\
\text { 2007: }-1.45(-1.4) \\
2012:-0.95\end{array}$ \\
\hline QBOW years & $\begin{array}{l}\text { 1980/81: } 0.95 \\
\text { 1982/83: } 1.11(2.2) \\
\text { 1985/86: } 0.96 \\
\text { 1987/88: } 0.66(0.8) \\
\text { 1988/89: } 0.95(-1.7) \\
\text { 1990/91: } 0.69 \\
\text { 1992/93: } 0.58 \\
\text { 1993/94: } 0.66 \\
\text { 1995/96: } 0.76(-0.9) \\
\text { 1997/98: } 0.71(2.2) \\
\text { 1999/00: } 1.03(-1.7) \\
\text { 2002/03: } 0.54(0.9) \\
\text { 2004/05: } 0.62 \\
\text { 2006/07: } 0.93 \\
\text { 2008/09: } 1.00(-0.8) \\
\text { 2009/10: } 0.60(1.5) \\
\text { 2013/14: } 0.90\end{array}$ & $\begin{array}{l}\text { 1979: } 0.79 \\
\text { 1981: } 1.01 \\
\text { 1983: } 1.14(1.3) \\
\text { 1985: } 0.50(-0.8) \\
\text { 1986: } 1.05 \\
\text { 1988: } 0.66 \\
\text { 1989: } 0.87(-0.8) \\
\text { 1991: } 0.60 \\
\text { 1993: } 0.81 \\
\text { 1995: } 0.62 \\
\text { 2000: } 1.12(-0.8) \\
\text { 2002: } 0.72 \\
\text { 2005: } 0.88 \\
\text { 2007: } 0.90 \\
\text { 2009: } 1.05 \\
\text { 2011: } 0.59 \\
\text { 2012: } 0.52 \\
\text { 2014: } 1.06\end{array}$ & $\begin{array}{l}\text { 1980: } 0.88 \\
\text { 1981: } 0.75 \\
\text { 1983: } 0.97 \\
\text { 1985: } 0.73 \\
\text { 1986: } 0.78 \\
\text { 1988: } 0.86(-1.3) \\
\text { 1990: } 0.79 \\
\text { 1993: } 0.76 \\
\text { 1995: } 0.91 \\
\text { 1997: } 1.09(1.6) \\
\text { 1999: } 0.80(-1.1) \\
\text { 2000: } 1.10 \\
\text { 2002: } 0.74(0.8) \\
\text { 2004: } 0.82 \\
\text { 2006: } 0.76 \\
\text { 2008: } 0.70 \\
\text { 2009: } 0.79 \\
\text { 2011: } 0.98 \\
\text { 2013: } 0.64 \\
\text { 2014: } 0.63\end{array}$ & $\begin{array}{l}\text { 1980: } 0.94 \\
\text { 1983: } 0.75(-0.8) \\
\text { 1985: } 0.95 \\
\text { 1986: } 0.70(0.9) \\
\text { 1988: } 0.87(-1.5) \\
\text { 1990: } 0.76 \\
\text { 1993: } 0.83 \\
\text { 1995: } 0.84(-1.0) \\
\text { 1997: } 0.96(2.3) \\
\text { 1999: } 0.94(-1.3) \\
\text { 2000: } 0.66 \\
\text { 2002: } 0.68(1.2) \\
\text { 2004: } 0.62 \\
\text { 2006: } 0.85 \\
\text { 2008: } 0.62 \\
\text { 2009: } 0.84(1.0) \\
\text { 2010: } 0.53(-1.7) \\
\text { 2011: } 0.91(-1.1) \\
\text { 2013: } 0.81 \\
\text { 2015: } 0.87(2.4)\end{array}$ \\
\hline
\end{tabular}

Space-time spectra are computed for each of the four standard seasons-December-February (DJF), March-May (MAM), June-August (JJA), and September-November (SON)-by Fourier transforming 96-day segments centered on these seasons. The power spectrum is computed for each year and then averaged separately over the years that are either easterly or westerly phases of the QBO. Spectral peaks are identified by normalizing the raw spectra by an estimate of the red background spectrum, constructed following Wheeler and Kiladis (1999). Here, we form the seasonal background spectrum separately for QBOE and QBOW for identifying evidence of spectral peaks in each period. This approach does not reveal differences in total power for particular wave modes between QBOE and QBOW. However, the difference in actual power is estimated by forming indices for each wave mode based on bandpassfiltered power (described below).
We concentrate on the equatorially symmetric (Kelvin and Rossby waves) and antisymmetric (mixed Rossby-gravity wave) spectra around the equator between $15^{\circ} \mathrm{S}$ and $15^{\circ} \mathrm{N}$. The high-frequency gravity waves are not considered in this study, but no evidence of any significant differences is found in their seasonalmean power between QBOE and QBOW (not shown). To highlight the differences in actual power between QBOE and QBOW for the CCEWs, we also make use of OLR that has been bandpass filtered in wavenumber and frequency space to discriminate the MJO and the other CCEWs. The filtering for each wave type follows the specifications in Wheeler and Kiladis (1999). This filtering technique retains power for the range of frequencies that are bounded by the dispersion curves for each wave type with equivalent depths between 8 and $90 \mathrm{~m}$ and for a particular range of zonal wavenumbers. A two-dimensional space-time Fourier transform is applied to the entire OLR record (1979-2015), after 
removing the annual cycle and tapering to zero the first and last $5 \%$ of the time series. The CCEWs are extracted by applying inverse Fourier transform to the coefficients contained in the wavenumber-frequency domain bounded by the dispersion curves at specific equivalent depth [for details see section 4 of Wheeler and Kiladis (1999), and their Fig. 6]. The CCEWs are decomposed into either symmetric or antisymmetric components, while both the components are retained for the MJO. But our key results are not affected if we do not account for equatorial symmetry of the CCEWs. We also explore the impact of the QBO on all highfrequency (2-30-day period) convective variance and the non-MJO intraseaonal variance, which is defined as the difference between 30-120-day bandpass-filtered variance and the MJO filtered variance. Based on analysis of the space-time power spectrum, we did not detect any impacts of the QBO on the higher-frequency $(<2$-day period) inertio-gravity waves. Therefore, the inertio-gravity waves are not considered in the present study.

The vertical structure of the CCEWs are explored using daily mean horizontal and vertical winds and temperatures from ERA-Interim (Dee et al. 2011). These are available on a $0.75^{\circ}$ horizontal grid. We use the available 31 pressure-level data between 20 and $1000 \mathrm{hPa}(20,30,50,70,100,125,150,175,200,225,250$, $300,350,400,450,500,550,600,650,700,750,775,800$, $825,850,875,900,925,950,975,1000 \mathrm{hPa})$.

El Niño-Southern Oscillation (ENSO) has a strong impact on the seasonal anomalies of CCEW variance, which might interfere with the evaluation of any impact stemming from the QBO. Although previous analysis revealed limited impact of ENSO on the QBO-MJO interaction (e.g., Nishimoto and Yoden 2017), primarily because ENSO does not strongly impact the MJO activity on seasonal time scales during austral summer (e.g., Hendon et al. 1999, 2007), we cannot exclude a potentially strong impact of ENSO on seasonal variation of CCEW activity. We thus examine QBO impacts on CCEWs by excluding strong El Niño or La Niña events. The key results presented here are, however, not sensitive to inclusion of the ENSO years. We identify El Niño and La Niña years using the Oceanic Niño index (ONI), which is based on the 3-month running-mean anomaly of the Niño-3.4 sea surface temperature index. A season during strong El Niño or La Niña is opted out when the seasonal value of the ONI is greater than 0.75 or less than -0.75 , respectively. The ONI index is obtained from http://origin.cpc.ncep.noaa.gov/products/analysis_ monitoring/ensostuff/ONI_v5.php. The concurrent ENSO years that are excluded from our analysis are indicated in Table 1.

\section{Space-time spectral analysis}

We begin our assessment of CCEWs by examining the normalized space-time power spectrum of equatorially symmetric and antisymmetric OLR during QBOE and QBOW phases, excluding the strong El Niño and La Niña years. The normalized symmetric spectra for DJF and MAM seasons are displayed in Fig. 1, while the same for JJA and SON are displayed in Fig. 2. As there is little indication of any difference between QBOE and QBOW for the antisymmetric spectra, the respective normalized antisymmetric spectra are displayed in Fig. S1 in the online supplemental material.

The normalized symmetric spectra in Figs. 1 and 2 reveal spectral peak for the MJO that is shifted to lower frequency during easterly phases of the QBO in the DJF season (see also Fathullah et al. 2017). The differences in the MJO peak during the other seasons are minor, confirming previous studies that have shown the impact of the QBO on the MJO is primarily limited to the austral summer season (e.g., Yoo and Son 2016; Marshall et al. 2017).

The only other obvious difference in the normalized symmetric spectra between QBOE and QBOW years is the apparently stronger spectral peak for the convectively coupled Kelvin waves during QBOE in the MAM season (Fig. 1). Otherwise, the symmetric CCEWs appear to be largely insensitive to the phase of the QBO in all seasons. This null result also holds for the higher frequency inertio-gravity waves (not shown in Figs. 1 and 2). The normalized antisymmetric spectra (Fig. S1) also do not show any obvious differences in the spectral peaks associated with mixed Rossby-gravity waves between QBOE and QBOW. However, as we normalize the seasonal raw spectra by a background spectrum, formed separately during QBOE and QBOW, this approach cannot reveal the differences in total power.

To quantify the variation of the total power, or equivalently seasonal-mean amplitude of the wave modes between QBOE and QBOW, we compute the ratio of seasonal-mean raw (unnormalized) power during QBOE compared to the power during QBOW for each wave type (Table 2). We compute the seasonalmean power for each wave by using bandpass-filtered data of the entire period (1979-2015) and then forming averaged variance across all the longitudes between $0^{\circ}$ and $360^{\circ}$ in the domain $15^{\circ} \mathrm{S}-15^{\circ} \mathrm{N}$. This computation is performed separately for each season of QBOE and QBOW years by excluding the same ENSO years as before. Note that the mean power of each wave is computed over the same spatial domain as we use for the space-time spectra displayed in Figs. 1 and 2. We also 

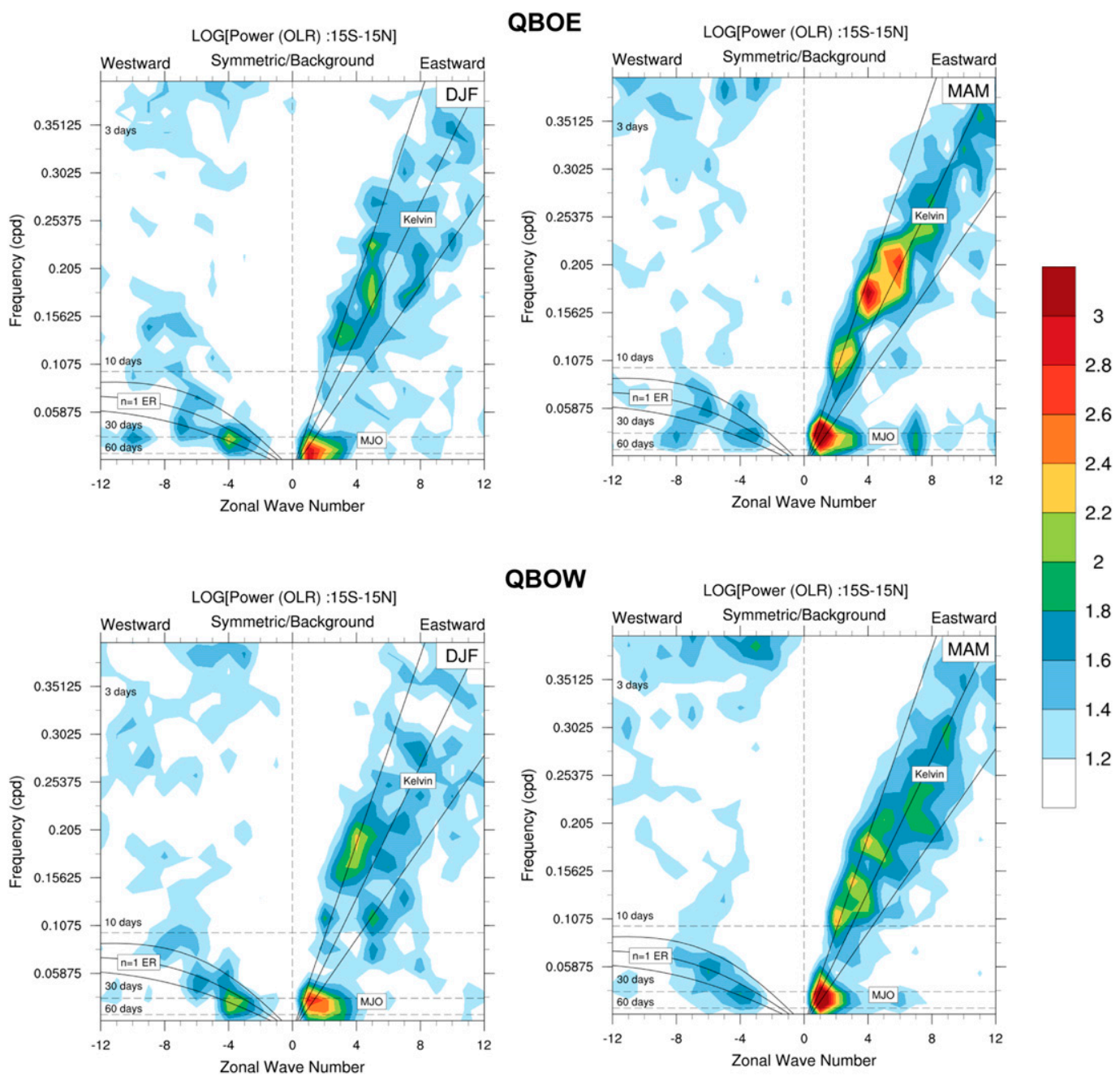

FIG. 1. Space-time power spectra of symmetric OLR anomalies averaged over $15^{\circ} \mathrm{S}-15^{\circ} \mathrm{N}$ and normalized by an estimate of the red background spectrum. Power was computed for non-ENSO (top) QBO easterly phases and (bottom) QBO westerly phases for (left) DJF and (right) MAM during 1979-2015. The contour interval is 0.2, with values greater than 1.2 estimated to be significant at the $5 \%$ level. Dispersion curves for the $n=1$ Kelvin and $n=1$ equatorial Rossby (ER) waves are plotted for equivalent depths of 12, 25, and $50 \mathrm{~m}$. Spectra were computed using 96-day segments for each easterly and westerly year and then averaged over all non-ENSO QBO years, yielding an effective bandwidth of (96 days) ${ }^{-1}$.

extend this calculation to include all high-frequency (2-30-day period) convective variance and the nonMJO component of intraseasonal variance.

To assess statistically significant differences in the total filtered power, we adopt a permutation resampling approach to estimate the significance of the ratio of bandpass-filtered variances during QBOE and QBOW. Our null hypothesis is that the variances averaged during QBOE and QBOW are identical (i.e., the expected ratio of variance $=1)$. To resample, we first pool all of the non-ENSO years for each season and then randomly choose $\mathrm{N} 1$ and $\mathrm{N} 2$ years from this pool without replacement, where $\mathrm{N} 1$ and $\mathrm{N} 2$ are the number of non-ENSO QBOE and QBOW years, respectively (the numbers of years for each season can be determined from Table 1 ). We form the mean variance over the $\mathrm{N} 1$ and $\mathrm{N} 2$ samples and then form their ratio. By resampling, we form this ratio 1000 times. The $95 \%$ confidence interval about the null hypothesis is given by the 2.5 th and 97.5 th percentiles of the resampled ratios. The observed ratio is estimated to be significant at the $5 \%$ level if its value falls outside of this 2.5 th97.5th-percentile range.

The observed ratios of filtered variance in easterly and westerly phases of the QBO and the $95 \%$ confidence interval about the null hypothesis are given in Table 2 

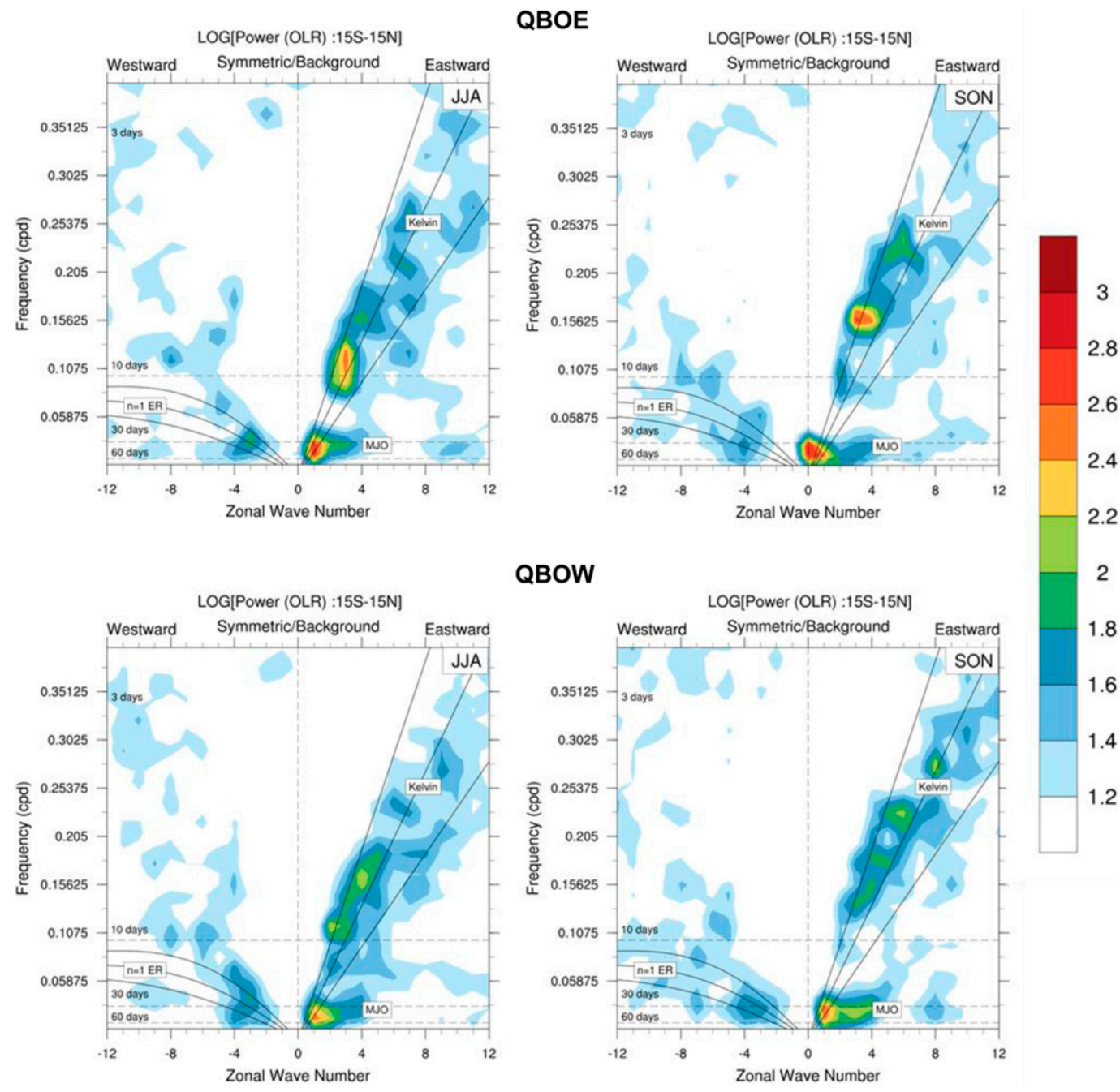

FIG. 2. As in Fig. 1, but for (left) JJA and (right) SON seasons.

for the MJO, symmetric Kelvin, $n=1$ Rossby, and antisymmetric mixed Rossby-gravity waves, and the total high-frequency and non-MJO intraseasonal variability. Confirming previous results, the seasonal-mean convective variance associated with the MJO during QBO easterly phases is found to be significantly stronger than during QBO westerly phases but only in DJF. The seasonal-mean variance of the MJO in DJF is $57 \%$ stronger during QBOE compared to its QBOW counterpart. There are no other significant differences at $p=5 \%$ between easterly and westerly phases of the QBO for the MJO in any other season or for any of the CCEWs. This null result carries over to all highfrequency variance and the non-MJO component of intraseasonal variance, suggesting that only the MJO during austral summer is modulated by the QBO. This result implies that previous studies (e.g., Collimore et al. 2003; Liess and Geller 2012) that have detected increased convective activity during QBOE were apparently seeing the impact due to the MJO during DJF. Although not significant at $p<5 \%$, the convectively coupled Kelvin waves during MAM show the next largest ratio, whereby Kelvin wave variance is $\sim 13 \%$ stronger during easterly phases of the QBO as compared to that during westerly phases. This increase is almost significant at $p=10 \%$ level, but it is a much weaker percentage increase in variance than for the MJO during DJF.

The strong modulation of MJO convective variance by the QBO during the austral summer season and the lack of modulation of the CCEWs are further quantified by computing the correlation between the 3-monthmean FUB QBO index and the 3-month-mean, tropically averaged filtered variance for the MJO, Kelvin, mixed Rossby-gravity and $n=1$ Rossby waves (Fig. 3). We consider all the years between 1979 and 2015 in this 
TABLE 2. Ratio of tropical-mean OLR variance (averaged over $15^{\circ} \mathrm{S}-15^{\circ} \mathrm{N}, 0^{\circ}-360^{\circ}$ ) for MJO, Kelvin, $n=1$ Rossby, mixed Rossbygravity waves, high-frequency ( $<30$ day), and non-MJO low-frequency (30-120 day) intraseasonal variability during easterly and westerly phases of the QBO, excluding the ENSO years of Table 1. The 95\% confidence interval about the null hypothesis of equal variances (i.e., ratio $=1$ ) is in parentheses. Observed ratios significant at $5 \%$ level are in boldface (only the MJO during DJF). The ratio for Kelvin wave variances during MAM (1.13) is judged to be significant at $p=10 \%$.

\begin{tabular}{lccrr}
\hline \hline & DJF & MAM & JJA & SON \\
\hline MJO & $\mathbf{1 . 5 7}(0.64-1.55)$ & $1.04(0.67-1.45)$ & $1.04(0.8-1.24)$ & $0.93(0.83-1.20)$ \\
Kelvin & $1.03(0.85-1.16)$ & $1.13(0.81-1.16)$ & $0.87(0.85-1.13)$ & $1.03(0.92-1.09)$ \\
$n=1$ Rossby & $1.01(0.83-1.20)$ & $1.03(0.77-1.24)$ & $1.03(0.79-1.22)$ & $1.02(0.83-1.20)$ \\
mixed Rossby-gravity & $1.02(0.88-1.13)$ & $1.05(0.81-1.14)$ & $0.9(0.85-1.14)$ & $1.0(0.89-1.12)$ \\
$<$ 30 days & $1.02(0.93-1.07)$ & $0.99(0.96-1.04)$ & $0.97(0.95-1.04)$ & $1.0(0.96-1.04)$ \\
non-MJO 30-120 days & $0.98(0.88-1.13)$ & $0.95(0.87-1.15)$ & $1.12(0.85-1.22)$ & $1.09(0.80-1.25)$ \\
\hline
\end{tabular}

calculation regardless of the strength of the QBO and ENSO. We also assess significance of the correlation using an $F$ test and estimate the effective sample size following Bretherton et al. (1999) by considering the lag-1 autocorrelations of the QBO and the filtered CCEW variance time series. The only significant correlation between the seasonal-mean variance and the QBO is for the MJO during austral summer, when the correlation peaks at about -0.6 . This negative correlation is comparable (but slightly weaker) to that reported by Yoo and Son (2016) and Marshall et al. (2017), who measured MJO activity using the seasonal-mean amplitude of the OMI (Kiladis et al. 2014) and the RMM indices (Wheeler and Hendon 2004), respectively. No significant correlation is found for any of the CCEWs in any season. However, the correlation of the QBO index with the convectively coupled Kelvin wave variance during MAM (and FMA) nearly passes the 5\% significance threshold, which is consistent with the ratio of filtered convective variances between the easterly and westerly phases of the QBO then being significant at $p \sim 10 \%$ (Table 2).

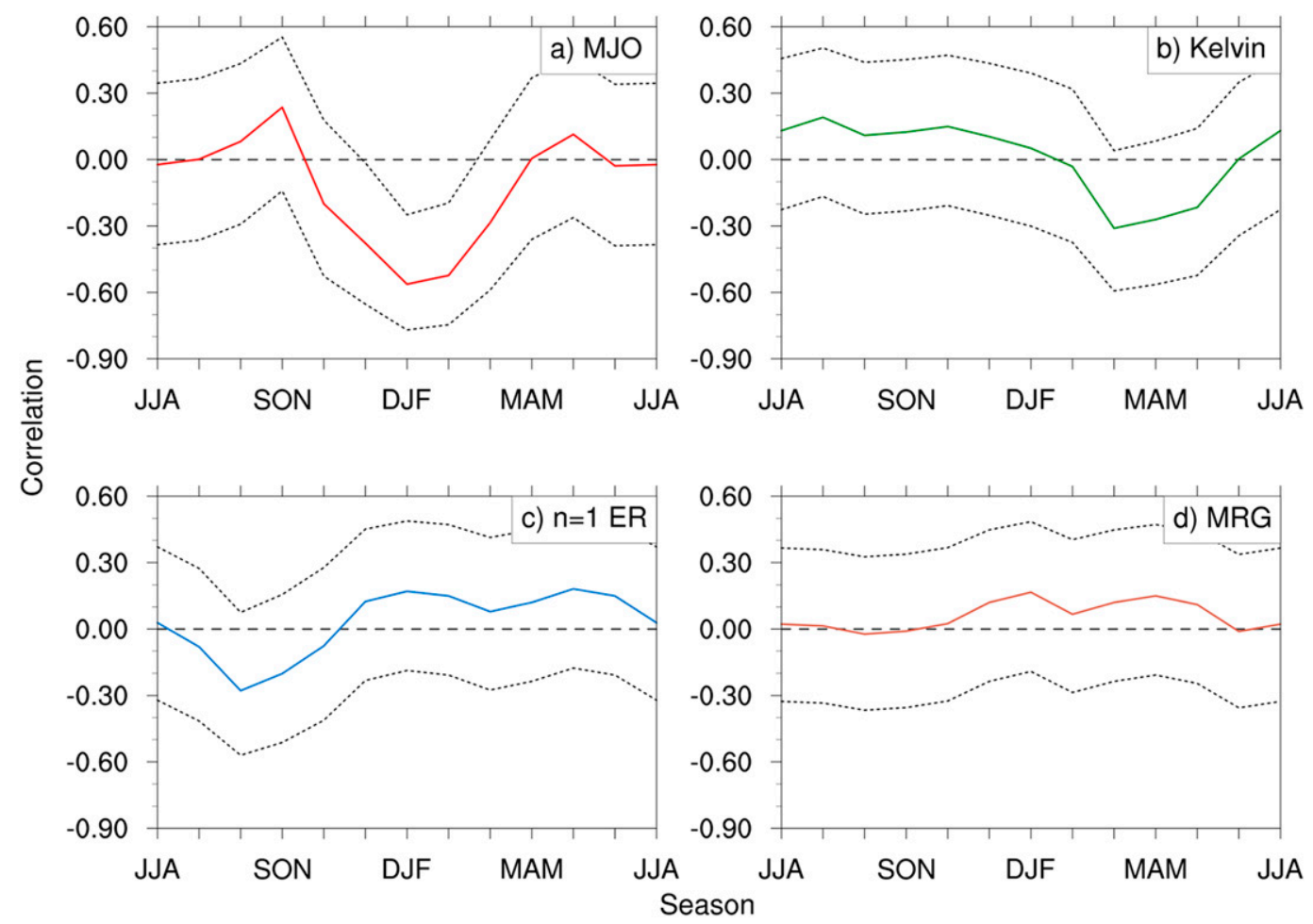

FIG. 3. Correlation between the QBO index and 3-month-mean (a) MJO, (b) Kelvin wave, (c) $n=1$ Rossby wave, and (d) mixed Rossby-gravity wave filtered OLR variance averaged over $15^{\circ} \mathrm{S}-15^{\circ} \mathrm{N}, 0^{\circ}-360^{\circ}$ during $1979-2015$. Dotted curves indicate the $95 \%$ confidence interval for the correlation. 

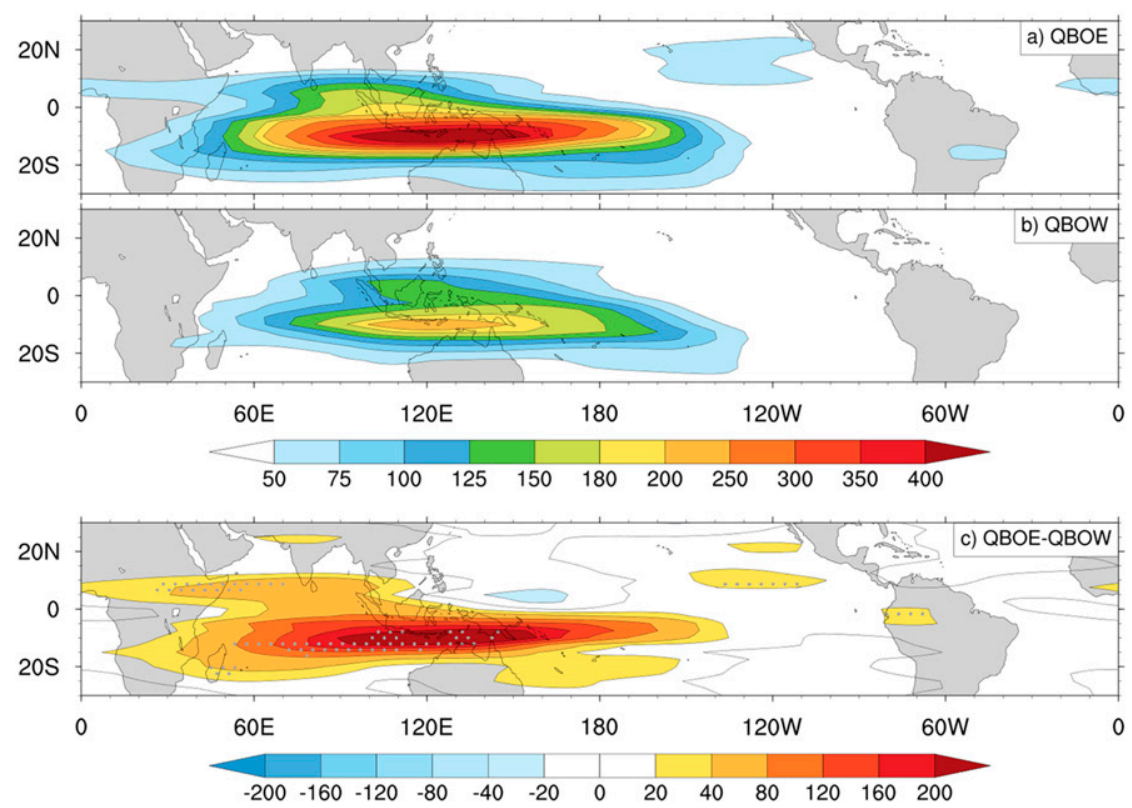

FIG. 4. MJO-filtered OLR variance $\left(\mathrm{W}^{2} \mathrm{~m}^{-4}\right)$ for DJF during (a) easterly and (b) westerly phases of the QBO, excluding ENSO years during 1979-2015. (c) Difference between (a) and (b), with stippling indicating significant differences at the $5 \%$ level.

\section{Mechanism of impact from the QBO}

Given the strong covariation of MJO activity during DJF with the QBO, why are the other CCEWs not similarly affected? A plausible explanation for the insensitivity of the equatorial Rossby and mixed Rossbygravity waves to the QBO is that their convective signals are less equatorially confined compared to the MJO, which might make them less sensitive to the equatorially concentrated variations of the QBO. However, the convectively coupled Kelvin waves are even more equatorially confined than the MJO, so lack of equatorial confinement cannot explain the lack of impact from the QBO on the Kelvin waves. And, although the relationship does not pass the 5\% significance level, the strongest relationship between seasonal-mean convectively coupled Kelvin wave activity and the QBO occurs during MAM rather than in DJF as for the MJO. So, an additional question is raised as to why the Kelvin wave activity is most related to the QBO during MAM, but at a level much weaker than for the MJO during DJF. The remaining part of the paper focuses on why there is a strong impact of the QBO on MJO activity during DJF but only a modest impact on Kelvin wave activity during MAM.

Further insight comes from maps of DJF-mean convective variance for the $\mathrm{MJO}$ during $\mathrm{QBOE}$ and $\mathrm{QBOW}$ years (Fig. 4), which show that the biggest impact of the QBO is just south of the equator in the Indian Ocean- western Pacific region where MJO convective variance is larger during QBOE. This region is where MJO convective activity is climatologically strongest and is consistent with results presented in Yoo and Son (2016), Son et al. (2017) and Marshall et al. (2017). Examination of the maps of non-MJO intraseasonal variance during QBOE and QBOW (Fig. S2) reveals that only the MJO component of the intraseasonal convective variance is significantly increased during DJF, consistent with the results in Table 2. In MAM, Kelvin wave convective variance is also enhanced in the equatorial Maritime Continent region during QBOE (Fig. 5). However, statistically significant enhancement is confined to a few grid points in the Maritime Continent region.

This leads to the question: can the destabilization argument of Hendon and Abhik (2018) be used to explain all of these observations? Hendon and Abhik (2018) hypothesized that the mechanism of interaction of the MJO with the QBO is via destabilization around the tropopause through a combination of direct cooling at $100 \mathrm{hPa}$ driven by the QBO during its easterly phase and by MJO-induced cooling around $100 \mathrm{hPa}$ above enhanced MJO convection. Together with the mid- to upper-tropospheric warm anomaly produced by the enhanced MJO convection (e.g., Holloway and Neelin 2007), these MJO-induced temperature anomalies act to destabilize the upper troposphere. This uppertropospheric destabilization is in phase with the MJO convection and leads to a more in-phase relationship of 

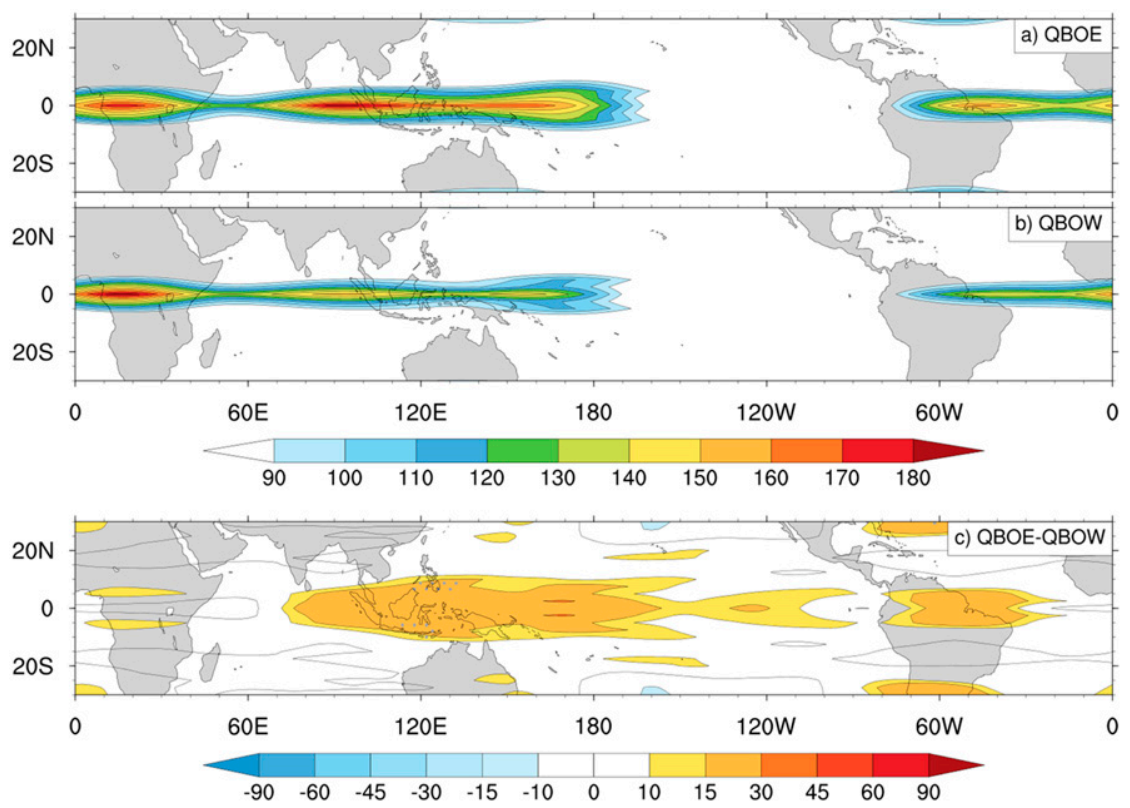

FIG. 5. As in Fig. 4, but for symmetric OLR power filtered for Kelvin waves during MAM season.

enhanced convection with the tropospheric temperature anomaly, thus indicating enhanced eddy energy production (e.g., Lin et al. 2005). This mechanism relies on the temperature perturbations driven by the MJO in the upper troposphere to be vertically aligned and to extend high enough to interact with the downward-extending temperature anomaly driven by the QBO.

The vertical structures of the equatorially averaged temperature, zonal and vertical winds, and OLR anomalies are displayed in Fig. 6 for the MJO in DJF and the Kelvin waves in MAM during QBOE and QBOW. Note that a narrower range of latitudes $\left(10^{\circ} \mathrm{S}-10^{\circ} \mathrm{N}\right)$ is used here for better focusing on the near-equatorial structure of the waves and their possible interaction with the QBOinduced tropopause temperature anomalies. The anomalies in Fig. 6 were formed by regression onto the MJO and Kelvin wave bandpass-filtered OLR time series, respectively, averaged over $10^{\circ} \mathrm{S}-10^{\circ} \mathrm{N}$ at $120^{\circ} \mathrm{E}$. The regressions are computed during DJF for the MJO and during MAM for the Kelvin waves and only during the non-ENSO years listed in Table 1. For display, the regression coefficients are scaled by a one standard deviation anomaly of the bandpass-filtered OLR time series in each case. Significance of the regression coefficients is assessed using a $t$ test on the equivalent correlation coefficients, with the effective sample size estimated following the same approach used in Fig. 3. The seasonalmean temperature anomaly associated with the QBO is displayed for illustrative purposes with contours and was computed as the mean difference of equatorially averaged zonal-mean temperature between both the QBO phases. The seasonal-mean temperature anomalies associated with the QBOE and QBOW are indicated in the top and bottom panels, respectively. Additionally, the evolution of the associated equatorially averaged OLR anomaly is displayed at the lower part of each panel.

For the MJO (Figs. 6a,b), a mid- to upper-tropospheric positive temperature anomaly occurs $\sim 5$ days ahead of the peak convection anomaly (negative OLR) and is overlain by a cold anomaly centered around $100 \mathrm{hPa}$. Enhanced MJO convection is associated with deep tropospheric upward motion, indicative that the tropospheric warm anomaly is diabatically driven (e.g., Virts and Wallace 2014). The upward motion "overshoots" into the lower stratosphere, where the cold cap appears to be adiabatically driven (e.g., Holloway and Neelin 2007). In comparison to QBOW, the cold cap-warm anomaly is stronger and more in phase with enhanced convection during QBOE, thus indicating more efficient eddy kinetic energy production (e.g., Lin et al. 2005). The seasonal-mean cold anomaly associated with QBOE in the lower stratosphere (contours in Fig. 6a) is found to extend downward to $\sim 100 \mathrm{hPa}$, where it appears to constructively add to the cold-cap anomaly above the enhanced MJO convection. Hendon and Abhik (2018) argued that this additional destabilization at the tropopause provided by the easterly phase of the QBO is what promotes stronger MJO activity during QBOE. Also apparent in Figs. $6 a$ and $6 \mathrm{~b}$ is that the temperature anomalies exhibit an eastward tilt with height into the lower stratosphere and these anomalies extend higher into the stratosphere during 

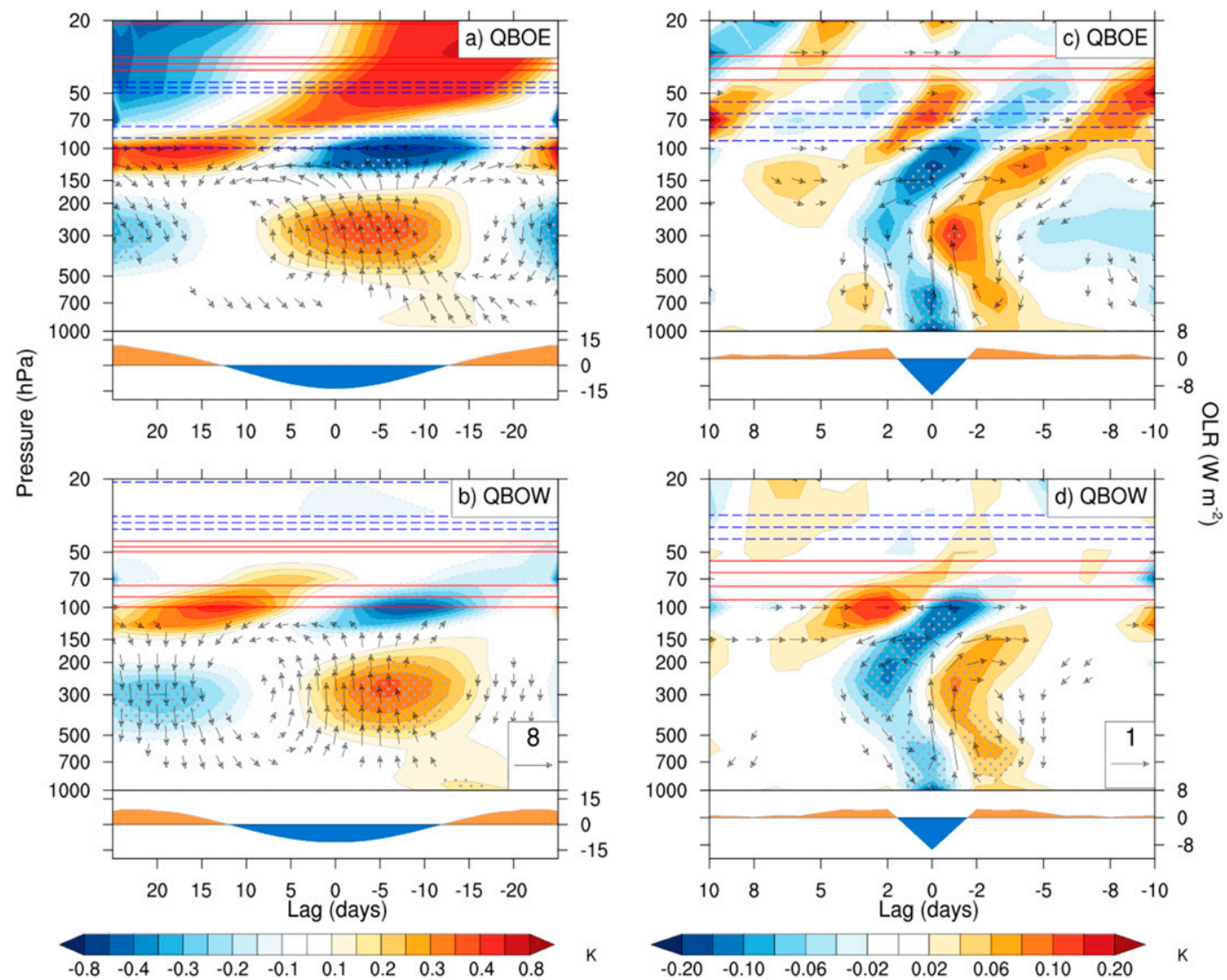

FIG. 6. Equatorially averaged $\left(10^{\circ} \mathrm{S}-10^{\circ} \mathrm{N}\right)$ temperature, zonal-vertical winds (vectors), and OLR (bottom curve in each panel; $\left.\mathrm{W} \mathrm{m}^{-2}\right)$ anomalies at $120^{\circ} \mathrm{E}$ regressed onto bandpass-filtered OLR $\left(10^{\circ} \mathrm{S}-10^{\circ} \mathrm{N}, 120^{\circ} \mathrm{E}\right)$ for (a), (b) the MJO during DJF and (c),(d) Kelvin waves during MAM. Regressions were formed for non-ENSO (top) QBOE and (bottom) QBOW during 1979-2015. Significant temperature anomalies at the 5\% level are stippled. Vectors are drawn if either the zonal or vertical wind component is significant at the $5 \%$ level. Pressure vertical velocity is multiplied by -1 so that an upward pointing vector indicates anomalous ascending motion. The vector scale in the lower right is indicative of a zonal wind anomaly with a magnitude of $10 \mathrm{~m} \mathrm{~s}^{-1}$ for the MJO and $1 \mathrm{~m} \mathrm{~s}^{-1}$ for the Kelvin wave. For vertical velocity, the vector scale is indicative of an anomaly with a magnitude of $2 \times 10^{-2} \mathrm{~Pa} \mathrm{~s}^{-1}$ for the MJO and $1 \times 10^{-2} \mathrm{~Pa} \mathrm{~s}^{-1}$ for the Kelvin wave. For display, the regression coefficients are multiplied by a one standard deviation anomaly of the bandpass-filtered OLR base-point time series. The seasonal-mean QBO temperature anomaly is contoured as positive anomalies in red solid and negative anomalies in blue dashed curves (interval of $0.1 \mathrm{~K}$ with the zero contour omitted).

QBOE. This difference of structure in the stratosphere is consistent with the notion that the MJO excites a short vertical wavelength Kelvin wave in the stratosphere (due to the low frequency of the MJO) and this excited Kelvin wave can propagate into the upper stratosphere during QBOE only (see also Fathullah et al. 2017).

In contrast, the Kelvin wave vertical structure (Figs. 6c,d) is shallower than the MJO in the troposphere and exhibits a distinctive "boomerang" structure about $250 \mathrm{hPa}$. Hence, there is much less in-phase relationship between the uppertropospheric warm anomaly, the overlying cold cap at $100 \mathrm{hPa}$ and the region of enhanced convection. Furthermore, because the Kelvin wave anomalies are less vertically stacked and shallow, the cooperative interaction of Kelvin wave-induced destabilization with the QBO-induced destabilization around the tropopause appears not to be effective.

The degree of covariation of MJO and Kelvin wave convection with the wave-induced reduction in uppertroposphere stability is quantified by forming the lagged regression along the equator of OLR and tropopause stability anomalies onto the same bandpassfiltered OLR base point (top panels in Fig. 7). We define the tropospause stability anomaly as the anomalous temperature difference between 100 and $200 \mathrm{hPa}\left(T_{100}-T_{200}\right)$. For the MJO (Figs. 7a-c), the convection and tropopause stability anomalies exhibit typical eastward propagation at about $5 \mathrm{~m} \mathrm{~s}^{-1}$ (e.g., 

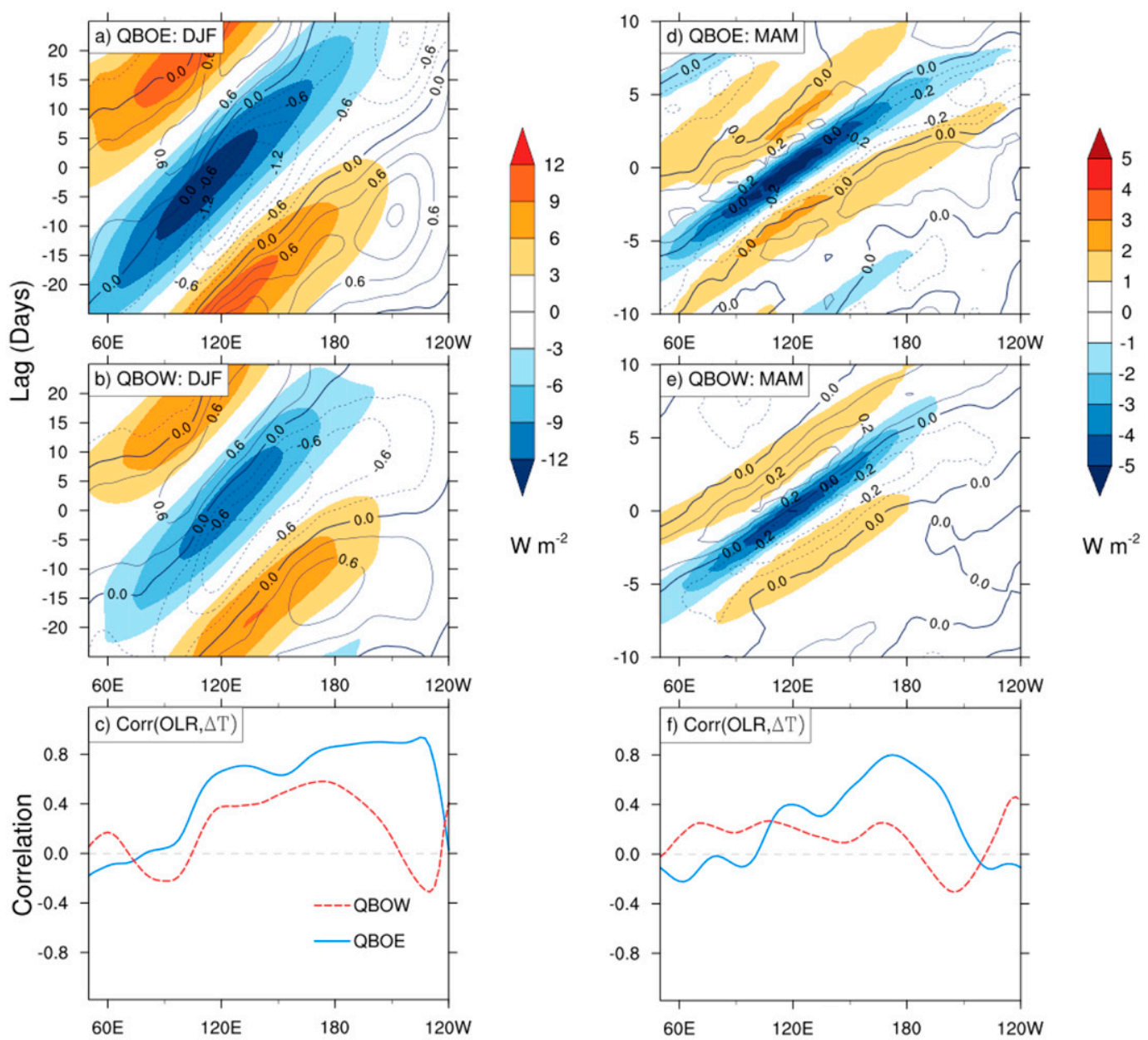

FIG. 7. Equatorially averaged $\left(10^{\circ} \mathrm{S}-10^{\circ} \mathrm{N}\right)$ anomalies of OLR (shading) and tropopause stability $\left(T_{100}-T_{200}\right.$; contours, solid curves for positive values and dashed curves for negative values) regressed onto (left) MJO and (right) Kelvin wave filtered OLR at $\left(10^{\circ} \mathrm{S}-10^{\circ} \mathrm{N}, 120^{\circ} \mathrm{E}\right)$ during DJF and MAM, respectively. (a),(d) Non-ENSO QBOE and (b),(e) non-ENSO QBOW. Contour interval for the OLR anomaly is $3 \mathrm{~W} \mathrm{~m}^{-2}$ for the MJO and $1 \mathrm{~W} \mathrm{~m}^{-2}$ for the Kelvin waves, while the contour interval for tropopause stability anomalies is $0.3 \mathrm{~K}$ for the MJO and $0.1 \mathrm{~K}$ for the Kelvin wave. The time axis runs from lag -25 days to lag +25 days for the MJO and lag -10 days to lag +10 days for the Kelvin waves. (c),(f) Correlation between OLR and tropopause stability anomalies at each longitude shown in (a), (b), (d), and (e), with a blue solid curve for non-ENSO QBOE and a red dotted curve for non-ENSO QBOW. For display, the regression coefficients are multiplied by a one standard deviation anomaly of the bandpass-filtered OLR at the base point.

Hendon and Salby 1994). During QBOE, enhanced convection clearly shifts to be more in-phase with decreased stratification as the MJO convection moves from the eastern Indian Ocean into the western Pacific $\left(90^{\circ} \mathrm{E}-180^{\circ}\right)$, indicative of the cooperative interaction of the QBO-induced destabilization with the MJOinduced temperature anomalies (e.g., Hendon and Abhik 2018). This in-phase behavior of convection with the tropopause stability is quantified, as in Hendon and Abhik (2018), by correlating the OLR and the stability anomalies $\left(T_{100}-T_{200}\right)$ at each longitude using the data displayed in the top panels of
Fig. 7. For the MJO, the correlation is more positive during QBOE compared to during QBOW from about $100^{\circ} \mathrm{E}$ to the date line, indicative that uppertropospheric destabilization of convection is more pronounced during easterly phases of the QBO (see also Hendon and Abhik 2018).

For the Kelvin wave (Figs. 7d-f), shorter period and faster eastward propagation are evident compared to the MJO. And, in contrast to the MJO, the OLR and upper-troposphere stability anomalies show much more tendency to be in quadrature, as would be expected for a freely propagating Kelvin wave (e.g., Kiladis et al. 2009). 

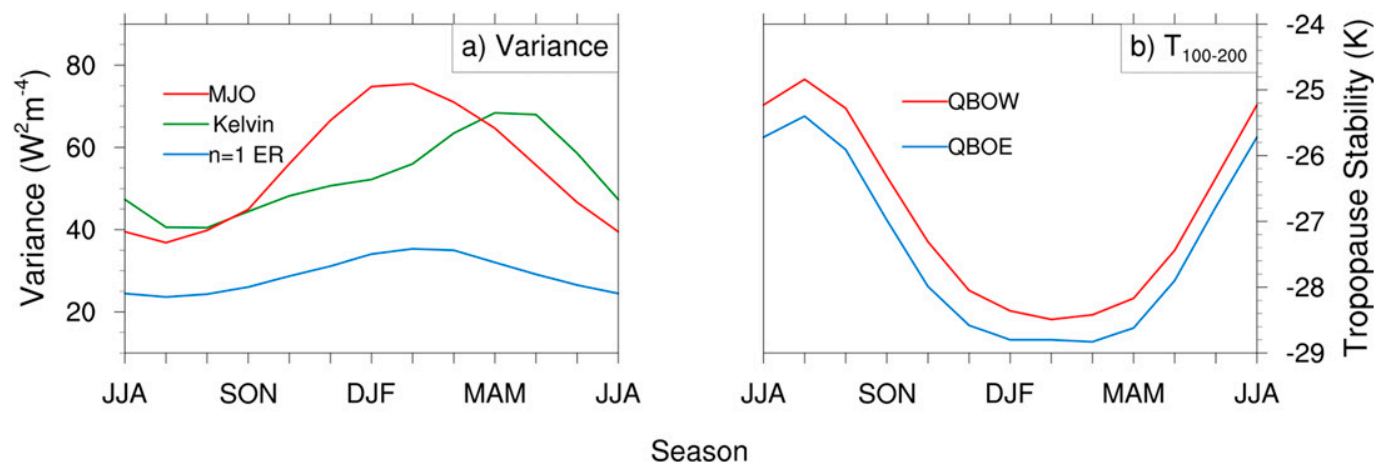

FIG. 8. (a) Seasonal cycle of 3-month-mean filtered OLR variance for the MJO (red), Kelvin wave (green), and $n=1$ Rossby wave (blue). Variance was averaged zonally and between $15^{\circ} \mathrm{S}$ and $15^{\circ} \mathrm{N}$ during $1979-2015$. (b) Seasonal cycle of zonal-mean tropopause stability $\left(T_{100}-T_{200}\right)$ averaged between $10^{\circ} \mathrm{S}$ and $10^{\circ} \mathrm{N}$ for QBOE (blue) and QBOW (red) during 1979-2015.

Some shift of the OLR to being more in phase with the temperature anomaly does occur across the Maritime Continent region during QBOE, but the positive correlation of OLR with upper-troposphere stability is weaker and more longitudinally confined than for the MJO. This positive but weak correlation during QBOE is supportive of the notion that the Kelvin waves are being modestly promoted by QBOE, but to a much lesser degree than for the MJO during DJF. The weaker promotion of Kelvin wave convection by destabilization in the upper troposphere during QBOE presumably reflects the more tilted vertical structure of the Kelvin wave in the upper troposphere, which does not allow it to tap into the additional destabilization at the tropopause provided by the QBO in the same fashion as the MJO.

\section{Seasonality of the QBO impact}

Insight into the seasonality of the impact of the QBO is gained by first examining the seasonality of the amplitude of the MJO and CCEWs near the equator using bandpass-filtered OLR variance (Fig. 8). Seasonal-mean MJO activity exhibits a well-known variation that peaks in austral summer (e.g., Salby and Hendon 1994), when the relationship between the MJO and the QBO is also found to be strongest. Similarly, the Kelvin wave activity seasonally peaks during austral autumn, which is also the season when its relationship with the QBO is strongest (based on Fig. 3), so it is feasible that the seasonal cycle of the strength of the wave convective activity is involved in the mechanism for both the MJO and Kelvin waves.

The strongest MJO activity also occurs when the tropopause temperatures are seasonally coldest during QBOE in the austral summer season (Fig. 8b). A weaker impact of the QBO on Kelvin wave activity might be expected to occur because convectively coupled Kelvin wave activity maximizes during MAM (Fig. 8a), after the tropopause has seasonally reached its coldest temperature (both seasonally and in response to the QBO; Fig. 8b). If the MJO-induced cooling at the tropopause above MJO convection is proportional to the strength of the MJO (which peaks during DJF), then we might expect the strongest interaction of the MJO with the QBO to be during austral summer, when both the MJO activity is strongest and the tropopause temperature is seasonally coldest during easterly phases of the QBO. Similarly, we might expect a weaker impact of the QBO on the Kelvin waves because the strongest Kelvin wave activity and associated strongest tropopause temperature perturbations to occur during austral autumn, after the seasonal occurrence of the coldest tropopause temperatures during summer.

These ideas are further explored by computing the seasonal cycle of the magnitude of the MJO and Kelvin wave-induced temperature anomalies at the tropopause. We compute this by regressing equatorially averaged $\left(10^{\circ} \mathrm{S}-10^{\circ} \mathrm{N}\right)$ anomalies of $T_{100}-T_{200}$ onto respective bandpass-filtered OLR time series for the MJO and the Kelvin waves. We form the regression for each base point along the equator over $90^{\circ} \mathrm{E}-180^{\circ}$ and form the mean variance of the regressed $T_{100}-T_{200}$ anomalies for lags 0 to -5 days for the MJO and lags 0 to -2 days for the Kelvin waves. We use these negative lags based on Fig. 6 for better capturing the temperature anomalies that lead the convection anomalies. We compute the mean variance in 3-month overlapping windows for all years regardless of the phase of the QBO and ENSO strength (Fig. 9). The strongest tropopause temperature anomalies driven by the MJO are seen to peak sharply during austral summer, consistent with when the association of the 


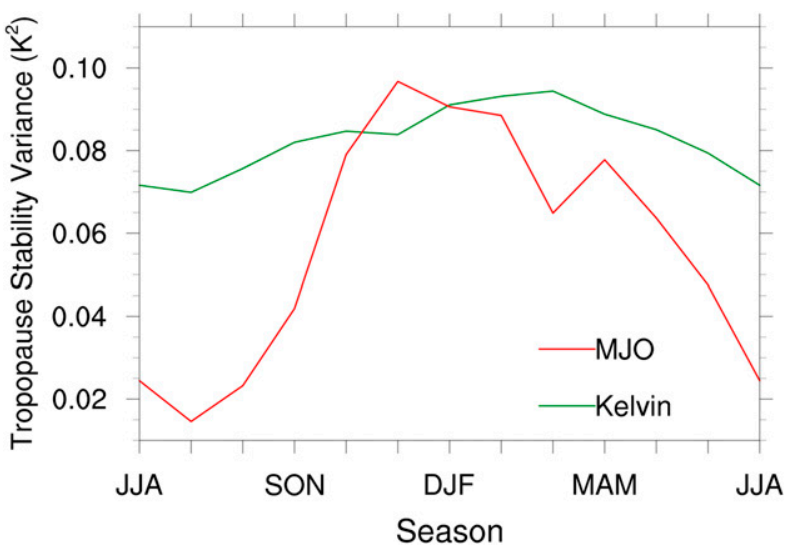

FIG. 9. Seasonal cycle of tropopause stability $\left(T_{100}-T_{200}\right)$ variance associated with the MJO (red) and the Kelvin waves (green). The stability variance was computed by first regressing the tropopause stability anomalies onto the MJO and Kelvin wave filtered OLR anomalies, respectively, at each longitude point. Variance of these regressed anomalies was computed using all lags between 0 and -5 days for the MJO and between 0 and -2 days for the Kelvin waves and averaged across all longitude base points between $90^{\circ} \mathrm{E}$ and $180^{\circ}$ with overlapping 3-month mean.

QBO with the MJO is strongest. The seasonal variation of the Kelvin wave-induced tropopause temperature anomalies is much weaker than for the MJO but is also seen to peak in the same season as when the association of the Kelvin waves with the QBO is greatest (i.e., austral autumn). The weaker relationship of the QBO with the Kelvin wave as compared to MJO is thus consistent with the difference in seasonal occurrence of the strongest tropopause temperature anomalies driven by these waves: the strongest MJO-induced anomalies occur during austral summer when the tropopause is seasonally coolest, but the strongest Kelvin wave-induced anomalies do not occur until $\sim 3$ months later, after the tropopause has begun to seasonally warm.

\section{Conclusions}

Seasonal variations of convectively coupled equatorial wave activity are found to be largely insensitive to the QBO, in contrast to seasonal-mean MJO activity that is markedly stronger during easterly phases of the QBO in austral summer. This conclusion is consistent with the earlier study of Fathullah et al. (2017). We further showed that only the MJO component of the intraseasonal (30-120-day period) convective variance significantly increases during DJF in QBOE. Although we focused on the CCEWs, the high-frequency (2-30-day period) convective variance is found to be not affected by the QBO in any season. This suggests that earlier studies (e.g., Collimore et al. 2003; Liess and Geller 2012) that reported an increase of convective activity during QBOE were probably detecting an impact from the MJO during DJF. Although not significant at $p=5 \%$, we presented some evidence that convectively coupled Kelvin wave activity is modestly enhanced during the easterly phase of the QBO in austral autumn, when convectively coupled Kelvin wave activity is seasonally strongest along the equator. However, this promotion of Kelvin wave activity by the easterly phase of the QBO is much weaker compared to impact on the MJO in DJF. The lack of impact on the other convectively coupled waves (e.g., Rossby waves and mixed Rossby-gravity waves) was argued to stem from their horizontal structure that does not yield an equatorially focused convective component that could be sensitive to the QBO. However, additional analysis is needed to support this claim. The peak relationship of the MJO with the QBO during DJF and of the Kelvin waves with the QBO during MAM is argued to reflect the strong seasonality of amplitude of these waves, which result in peak tropopause temperature anomalies during DJF and MAM, respectively.

The weaker impact on the Kelvin waves compared to the MJO was argued to stem largely from the more tilted and shallower vertical structure of the Kelvin waves, especially in the upper troposphere. This tilted vertical structure means that the destabilization mechanism proposed by Hendon and Abhik (2018) is not as effective for the Kelvin wave as for the MJO. The convectively driven upper-tropospheric warm anomaly and overlying cold cap at the tropopause are less in phase with the convective anomaly and cannot tap into the additional mean destabilization at the tropopause provided by the QBO. These results support the premise that the promotion of the MJO by the easterly phase of the QBO results from the unique structure of the MJO. The vertically stacked upper-tropospheric warm anomaly and overlying cold cap anomaly at $\sim 100 \mathrm{hPa}$ that are driven by MJO convection can tap into the destabilization about the tropopause driven by the easterly phase of the QBO, so to promote enhanced destabilization in phase with the convection. The more tilted vertical structure of the Kelvin waves renders this destabilization mechanism less effective.

This study reveals a consistent relationship between stronger convectively coupled wave activity and the spatial phasing of the convection and uppertropospheric temperature anomalies: stronger MJO activity and to a lesser degree Kelvin wave activity occurs during easterly phases of the QBO when there is a more in-phase relationship of convection, upper-tropospheric warm anomaly, and overlying tropopause cold anomaly. The more in-phase relationship of convection with an upper-tropospheric warm anomaly is indicative of enhanced eddy energy production (e.g., Lin et al. 2005); however, it does not indicate the causal mechanism. We presume it stems from the QBO easterly phase that directly promotes deeper and stronger $\mathrm{MJO}$ convection by 
additional mean destabilization at the tropopause. But it is also possible that cloud radiative effects may have an impact (e.g., Kim et al. 2015). The MJO is known to modulate cirrus clouds at the tropopause (e.g., Virts and Wallace 2014) and the easterly phase of the QBO acts to enhance the cirrus cloud (Son et al. 2017). Thus, it is possible that induced variation of the cirrus cloud could act to further destabilize the column as that has previously been shown for the MJO (Kim et al. 2015), thereby promoting stronger MJOs during QBOE. Cloudradiative forcing has been shown to weaken the other CCEWs in some models (e.g., Lin et al. 2007; Crueger and Stevens 2015), thus the enhanced cloud-radiative feedback during QBOE is preferably promoting the MJO compared to the other CCEWs. The lack of impact of the QBO on the other CCEWs thus motivates further study on the precise mechanism for exclusive promotion of the MJO by the QBO.

Acknowledgments. This work was supported by the Department of Agriculture and Water Resources of the Australian Government as part of its Rural R\&D for Profit Programme. SA acknowledges support from the Earth System and Climate Change Hub of the Australian government's National Environmental Science Programme (NESP). We thank Rob Colman, George N. Kiladis, and two anonymous reviewers for their critical comments on the earlier version of the manuscript that significantly improve the quality of the paper. ERAInterim reanalyses were obtained from ECMWF (http:// eccharts.ecmwf.int/datasets/). The daily interpolated OLR dataset was obtained from NOAA/ESRL PSD, Boulder, Colorado, (https://www.esrl.noaa.gov/psd/ data/gridded/data.interp_OLR.html). The FUB zonal wind index was accessed online (https://www.geo.fu-berlin. de/en/met/ag/strat/produkte/qbo/index.html). This research was carried out with the assistance of resources and services from the National Computational Infrastructure (NCI) of Australian Government and the analyses were performed using the NCAR Command Language (https://doi.org/ 10.5065/D6WD3XH5).

\section{REFERENCES}

Baldwin, M., and Coauthors, 2001: The quasi-biennial oscillation. Rev. Geophys., 39, 179-229, https://doi.org/10.1029/1999RG000073.

Bretherton, C. S., M. Widmann, V. P. Dymnikov, J. M. Wallace, and I. Bladé, 1999: The effective number of spatial degrees of freedom of a time-varying field. J. Climate, 12, 1990-2009, https://doi.org/10.1175/1520-0442(1999)012<1990:TENOSD> 2.0.CO;2.

Collimore, C. C., D. W. Martin, M. H. Hitchman, A. Huesmann, and D. E. Waliser, 2003: On the relationship between the QBO and tropical deep convection. J. Climate, 16, 2552-2568,
https://doi.org/10.1175/1520-0442(2003)016<2552:OTRBTQ> 2.0.CO;2.

Crueger, T., and B. Stevens, 2015: The effect of atmospheric radiative heating by clouds on the Madden-Julian oscillation. J. Adv. Model. Earth Syst., 7, 854-864, https://doi.org/10.1002/ 2015 MS000434.

Davis, S. M., C. K. Liang, and K. H. Rosenlof, 2013: Interannual variability of tropical tropopause layer clouds. Geophys. Res. Lett., 40, 2862-2866, https://doi.org/10.1002/grl.50512.

Dee, D. P., and Coauthors, 2011: The ERA-Interim reanalysis: Configuration and performance of the data assimilation system. Quart. J. Roy. Meteor. Soc., 137, 553-597, https://doi.org/ $10.1002 /$ qj. 828 .

Fathullah, N. Z., S. Lubis, and S. Setiawan, 2017: Characteristics of Kelvin waves and mixed Rossby-gravity waves in opposite QBO phases. IOP Conf. Series: Earth Environ. Sci., 54, 012032, https://doi.org/10.1088/1755-1315/54/1/012032.

Hendon, H. H., and M. L. Salby, 1994: The life cycle of the Madden-Julian oscillation. J. Atmos. Sci., 51, 2225-2237, https://doi.org/10.1175/1520-0469(1994)051<2225:TLCOTM> 2.0.CO;2.

_ , and S. Abhik, 2018: Differences in vertical structure of the Madden-Julian oscillation associated with the quasi-biennial oscillation. Geophys. Res. Lett., 45, 4419-4428, https://doi.org/ 10.1029/2018GL077207.

_ C. Chang, and J. D. Glick, 1999: Interannual variation of the Madden-Julian oscillation during austral summer. J. Climate, 12, 2538-2550, https://doi.org/10.1175/15200442(1999)012<2538:IVOTMJ>2.0.CO;2.

- M. C. Wheeler, and C. Zhang, 2007: Seasonal dependence of the MJO-ENSO relationship. J. Climate, 20, 531-543, https:// doi.org/10.1175/JCLI4003.1.

Holloway, C. E., and J. D. Neelin, 2007: The convective cold top and quasi equilibrium. J. Atmos. Sci., 64, 1467-1487, https:// doi.org/10.1175/JAS3907.1.

Kiladis, G. N., K. H. Straub, and P. T. Haertel, 2005: Zonal and vertical structure of the Madden-Julian oscillation. J. Atmos. Sci., 62, 2790-2809, https://doi.org/10.1175/JAS3520.1.

—, M. C. Wheeler, P. T. Haertel, K. H. Straub, and P. E. Roundy, 2009: Convectively coupled equatorial waves. Rev. Geophys., 47, RG2003, https://doi.org/10.1029/2008RG000266.

—, J. Dias, K. H. Straub, M. C. Wheeler, S. N. Tulich, K. Kikuchi, K. M. Weickmann, and M. J. Ventrice, 2014: A comparison of OLR and circulation-based indices for tracking the MJO. Mon. Wea. Rev., 142, 1697-1715, https://doi.org/10.1175/ MWR-D-13-00301.1.

Kim, D., M.-S. Ahn, I.-S. Kang, and A. D. Del Genio, 2015: Role of longwave cloud-radiation feedback in the simulation of the Madden-Julian oscillation. J. Climate, 28, 6979-6994, https:// doi.org/10.1175/JCLI-D-14-00767.1.

Lee, J. C. K., and N. P. Klingaman, 2018: The effect of the quasibiennial oscillation on the Madden-Julian oscillation in the Met Office Unified Model global ocean mixed layer configuration. Atmos. Sci. Lett., 19, e816, https://doi.org/10.1002/asl.816.

Liebmann, B., and C. A. Smith, 1996: Description of a complete (interpolated) outgoing longwave radiation dataset. Bull. Amer. Meteor. Soc., 77, 1275-1277, https://www.jstor.org/ stable/26233278.

Liess, S., and M. A. Geller, 2012: On the relationship between QBO and distribution of tropical deep convection.J. Geophys. Res., 117, D03108, https://doi.org/10.1029/2011JD016317.

Lin, J.-L., M. Zhang, and B. Mapes, 2005: Zonal momentum budget of the Madden-Julian oscillation: The source and strength of 
equivalent linear damping. J. Atmos. Sci., 62, 2172-2188, https://doi.org/10.1175/JAS3471.1.

- D. Kim, M.-I. Lee, and I.-S. Kang, 2007: Effects of cloud-radiative heating on atmospheric general circulation model (AGCM) simulations of convectively coupled equatorial waves. J. Geophys. Res., 112, D24107, https://doi.org/10.1029/2006JD008291.

Lindzen, R. S., and J. R. Holton, 1968: A theory of the quasibiennial oscillation. J. Atmos. Sci., 25, 1095-1107, https:// doi.org/10.1175/1520-0469(1968)025<1095:ATOTQB>2.0.CO;2.

Marshall, A. G., H. H. Hendon, S.-W. Son, and Y. Lim, 2017: Impact of the quasi-biennial oscillation on predictability of the Madden-Julian oscillation. Climate Dyn., 49, 1365-1377, https://doi.org/10.1007/s00382-016-3392-0.

Martin, Z., S. Wang, J. Nie, and A. Sobel, 2019: The impact of the QBO on MJO convection in cloud-resolving simulations. J. Atmos. Sci., 76, 669-688, https://doi.org/10.1175/JAS-D-18-0179.1.

Matsuno, T., 1966: Quasi-geostrophic motions in the equatorial area. J. Meteor. Soc. Japan, 44, 25-43, https://doi.org/10.2151/ jmsj1965.44.1_25.

Naujokat, B., 1986: An update of the observed quasi-biennial oscillation of the stratospheric winds over the tropics. J. Atmos. Sci., 43, 1873-1877, https://doi.org/10.1175/1520-0469(1986) 043<1873:AUOTOQ > 2.0.CO;2.

Nie, J., and A. H. Sobel, 2015: Responses of tropical deep convection to the QBO: Cloud-resolving simulations. J. Atmos. Sci., 72, 3625-3638, https://doi.org/10.1175/JAS-D-15-0035.1.

Nishimoto, E., and S. Yoden, 2017: Influence of the stratospheric quasi-biennial oscillation on the Madden-Julian oscillation during austral summer. J. Atmos. Sci., 74, 1105-1125, https:// doi.org/10.1175/JAS-D-16-0205.1.

Salby, M. L., and H. H. Hendon, 1994: Intraseasonal behavior of clouds, temperature, and motion in the tropics. J. Atmos. Sci., 51, 2207-2224, https://doi.org/10.1175/1520-0469(1994) $051<2207$ :IBOCTA $>2.0$. CO 2 .
Sobel, A., and E. Maloney, 2013: Moisture modes and the eastward propagation of the MJO. J. Atmos. Sci., 70, 187-192, https:// doi.org/10.1175/JAS-D-12-0189.1.

Son, S.-W., Y. Lim, C. Yoo, H. H. Hendon, and J. Kim, 2017: Stratospheric control of the Madden-Julian oscillation. J. Climate, 30, 1909-1922, https://doi.org/10.1175/JCLI-D-16-0620.1.

Virts, K. S., and J. M. Wallace, 2014: Observations of temperature, wind, cirrus, and trace gases in the tropical tropopause transition layer during the MJO. J. Atmos. Sci., 71, 1143-1157, https://doi.org/10.1175/JAS-D-13-0178.1.

Wang, B., and G. Chen, 2017: A general theoretical framework for understanding essential dynamics of Madden-Julian oscillation. Climate Dyn., 49, 2309-2328, https://doi.org/10.1007/ s00382-016-3448-1.

Wheeler, M., and G. N. Kiladis, 1999: Convectively coupled equatorial waves: Analysis of clouds and temperature in the wavenumber-frequency domain. J. Atmos. Sci., 56, 374-399, https:// doi.org/10.1175/1520-0469(1999)056<0374:CCEWAO >2.0.CO;2. , and K. M. Weickmann, 2001: Real-time monitoring and prediction of modes of coherent synoptic to intraseasonal tropical variability. Mon. Wea. Rev., 129, 2677-2694, https:// doi.org/10.1175/1520-0493(2001)129<2677:RTMAPO>2.0.CO;2.

_, and H. H. Hendon, 2004: An all-season real-time multivariate MJO index: Development of an index for monitoring and prediction. Mon. Wea. Rev., 132, 1917-1932, https://doi.org/ 10.1175/1520-0493(2004)132<1917:AARMMI>2.0.CO;2.

, G. N. Kiladis, and P. J. Webster, 2000: Large-scale dynamical fields associated with convectively coupled equatorial waves. J. Atmos. Sci., 57, 613-640, https://doi.org/10.1175/15200469(2000)057<0613:LSDFAW >2.0.CO;2.

Yoo, C., and S.-W. Son, 2016: Modulation of the boreal wintertime Madden-Julian oscillation by the stratospheric quasi-biennial oscillation. Geophys. Res. Lett., 43, 1392-1398, https://doi.org/ 10.1002/2016GL067762. 